\title{
Adding Silica Nanoparticles to Improve the Demulsification Process in a Crude Oil Central Processing Facility: A Techno-economic Analysis
}

\author{
Shireen A. Hassan' ${ }^{1}$ Babiker K. Abdalla ${ }^{2}$, and Mustafa A. Mustafa ${ }^{\text {* }}$ \\ ${ }^{1}$ Department of Chemical Engineering, Faculty of Engineering, University of Khartoum, Khartoum, Sudan. \\ ${ }^{2}$ Chemical Engineering, Karari University, Khartoum, Sudan. \\ ${ }^{3}$ Materials and Nanotechnology Research Centre, Faculty of Engineering, University of Khartoum, Khartoum, \\ Sudan.
}

"Corresponding author E-mail: Dr.mustafa.abbas@gmail.com

Received: $3^{\text {rd }}$ October 2021

Accepted for publication: $16^{\text {th }}$ January 2022

Published: $17^{\text {th }}$ February 2022

\begin{abstract}
In this study, a techno-economic evaluation of the use of silica nanoparticles to enhance the demulsification process in crude oil has been investigated. A software model has been developed in MS Excel of the central processing facility (CPF) treating Fula heavy crude oil in Balila, Sudan. A sensitivity analysis of key parameters on production cost and Net Present Value (NPV) has been carried out for different flowsheet selection options. Comparison of flowsheets on equal plant capacity basis results in a 19\% reduction in the production cost, whereas comparison on fixed annual crude oil processing basis results in a reduction in production cost of only $3.7 \%$.
\end{abstract}

Keywords: Demulsification, Nanoparticles, Techno-economic,

\section{Introduction}

Removing produced water from the crude oil is crucial as it may cause many technical problems like dripping and corrosion of pipes [1]. Furthermore, it is important for the crude oil to meet the required international specifications prior to export. Produced water mixes with the crude oil in two ways: as free water, which settles down rapidly by gravity in sedimentation tanks, and as an emulsion, which disperses in the form of droplets in the oil phase. Many studies have been conducted to improve the demulsification process in an efficient and rapid manner. One of which is based on the addition of silica 
nano-particles, to commonly used chemical demulsifiers, to enhance their effectiveness in removing the emulsion [2, 3]. Hassan et al. [3] showed good progress where both a 159\% increase in the percentage of water removed and acceleration of the demulsification process were achieved. The addition of the silicananoparticles requires only an ultrasonic homogenizer unit to disperse the powder in water and form a stable and uniform suspension at a concentration of $60 \mathrm{ppm}$. The suspension should be injected into the crude oil inlet header and raw crude manifold simultaneously with the chemical demulsifier at a ratio of 1:0.5 for the demulsifier to nano-particle suspension. This work was motivated by the technological viability of this method to investigate its economic feasibility through a detailed techno-economic analysis.

\section{Materials and Methods}

\section{Model components}

The CPF is assumed to consist of a heavy crude manifold, a sand trap, two heat exchangers. Around $30 \%$ of the crude is heated by vis-braking hot oil in another two heat exchangers to a temperature of $75^{\circ} \mathrm{C}$. The heated crude oil is then sent to the degas pipes where the free gas will be vented from the top of the pipes. Oil and water from the degas pipes are sent to first-stage sedimentation tanks and then to second-stage sedimentation tanks where the oil and water are separated by gravity and chemical demulsifiers. The final water cut of the separated crude should be less than $0.5 \%$. The dehydrated crude then enters the surge tanks and is pumped through five transfer pumps to the shipping tanks and by another three centrifugal pumps to the metering skid (figure 1). The assumptions for the developed model are shown in Table 1.

\section{Capital Cost of the CPF Model}

The capital and operating costs of the CPF plant were calculated based on the estimated costs of the main equipment of the plant. The heat exchangers, sedimentation tanks, and surge tanks costs were estimated from the correlation [4]:

$$
\mathrm{C}_{\mathrm{e}}=\mathrm{a}+\mathrm{b} S^{n}
$$

where $C_{e}$ is the purchased equipment cost, $S$ is the characteristic size parameter, $a$ and $b$ are the cost constants, and $\mathrm{n}$ is the index for that type of equipment.

The shipping tanks' cost is estimated by Milligan [5]. The data for the rest of the equipment were obtained from the historical prices of an existing CPF plant. All of the costs were updated to 2019 by using the cost escalation method. Also, a location factor of two was used to adjust the prices. The fixed capital cost was estimated by using the factorial method [4]. The following equation gives the fixed capital cost as a function of the total purchase equipment cost.

$$
\mathrm{c}_{\mathrm{f}}=4.7 \sum \mathrm{C}_{\mathrm{e}}
$$


Where: $C_{f}=$ fixed capital cost, $C_{e}=$ the total delivered cost of all the major equipment items like storage tanks and heat exchangers, and the constant number is the Lang factor in a fluid plant.

Working capital was taken as $15 \%$ of the fixed capital. The total investment was calculated as the sum of the two costs (Table 2).

Table 1: Base case assumptions for the CPF

\begin{tabular}{|c|c|}
\hline Information & Value \\
\hline Feed flow rate of crude oil (BOPD) & 50,000 \\
\hline Percentage of water in feed & $70 \%$ \\
\hline GOR & 3.5 \\
\hline Lang factor & 4.74 \\
\hline No. Of operating days $(\mathrm{d} / \mathrm{y})$ & 365 \\
\hline Price of crude oil $(\$ / b b l)$ & 60 \\
\hline Percentage of crude heated by vis-broken hot oil & $30 \%$ \\
\hline Project life (years) & 30 \\
\hline Demulsifier concentration (ppm) & 50 \\
\hline Unit price of demulsifier $(\$ / \mathbf{l})$ & 4.5 \\
\hline Price of nanoparticles (\$/ kg) & 1,600 \\
\hline Interest rate & $12 \%$ \\
\hline
\end{tabular}

Table 2: Capital Cost Estimation

\begin{tabular}{|c|c|c|c|c|c|c|}
\hline Equipment & $\begin{array}{l}\text { No. of } \\
\text { units }\end{array}$ & Capacity & $\begin{array}{l}\text { Cost } \\
\text { base }\end{array}$ & Cost \$/unit & $\begin{array}{l}\text { Updated cost } \\
\text { (2019) \$/unit }\end{array}$ & Cost (\$) \\
\hline Heat Exchanger & 4 & $6.12 \mathrm{MW}$ & 2007 & 500,000 & 611,162 & $2,444,646$ \\
\hline Sedimentation Tank & 4 & $5000 \mathrm{~m}^{3}$ & 2007 & $2,000,000$ & $2,444,646$ & $9,778,584$ \\
\hline Surge Tank & 2 & $1000 \mathrm{~m}^{3}$ & 2007 & 950,000 & $1,161,207$ & $2,322,414$ \\
\hline Sand Trap & 1 & - & 1998 & 245,000 & 413,294 & 413,294 \\
\hline Gas Boot (De-gas pipe) & 2 & - & 1998 & 350,000 & 590,420 & $1,180,839$ \\
\hline Transfer Pumps & 9 & - & 1998 & 760,000 & $1,282,054$ & $11,538,485$ \\
\hline Metering System & 3 & $\begin{array}{l}60,000 \\
\text { BOPD }\end{array}$ & 1998 & $2,500,000$ & $4,217,282$ & $12,651,847$ \\
\hline Shipping Tank & 5 & $20000 \mathrm{~m}^{3}$ & 2014 & $4,000,000$ & $4,038,981$ & $20,194,903$ \\
\hline Total equipment cost & & & & & & $60,525,011$ \\
\hline Fixed capital & & & & & & $286,888,554$ \\
\hline \multicolumn{6}{|l|}{ Working capital } & $43,033,283$ \\
\hline Total investment & & & & & & $\mathbf{3 2 9 , 9 2 1 , 8 3 7}$ \\
\hline
\end{tabular}

\section{Production Cost Calculation}

The operating costs are divided into fixed and variable costs. Operating labour, supervision, direct salary overhead, the maintenance, taxes and insurance, rent of land, and general plant overhead are all 
part of fixed costs. The variable cost in this case consists of the utilities, consumables, and the chemical demulsifier, added separately from the utilities. Sales expenses, general overheads, and R\&D costs are grouped as indirect costs and taken as $30 \%$ of the direct production costs (fixed and variable) see table 3 . The addition of the silica nanoparticles requires an ultrasonic homogenizer (probe sonicator) with a high-capacity recirculating chiller. The estimated cost for the addition of this unit is shown as $\$ 11,000$. The price of the silica nanoparticles is set at $\$ 1,600$ per $\mathrm{kg}$. Hassan et al. [3], showed how the use of silica nanoparticles resulted in an average reduction in treatment time of $24 \%$.

Table 3: Operating cost estimation

\begin{tabular}{lc}
\hline Item & Cost (\$) \\
\hline Variable costs & 665,264 \\
\hline Demulsifier & $1,434,703$ \\
\hline Consumables & $9,581,053$ \\
\hline Utilities & $\mathbf{1 1 , 8 2 4 , 4 5 5}$ \\
\hline Sub Total & \\
\hline Fixed costs & $14,347,035$ \\
\hline Maintenance & 480,000 \\
\hline Operating Labour & 96,000 \\
\hline Supervision & 240,000 \\
\hline Plant overheads & 144,000 \\
\hline Laboratory & $9,564,690$ \\
\hline Capital charges & $2,869,407$ \\
\hline Insurance & $5,738,814$ \\
\hline Local taxes & $\mathbf{3 3 , 4 7 9 , 9 4 5}$ \\
\hline Sub Total & $45,304,400$ \\
\hline Direct Production costs & $13,591,320$ \\
\hline Indirect cost & $58,706,874$ \\
\hline Annual Production cost & $\mathbf{3 . 2}$ \\
\hline Production costs $\mathbf{( \$ / b b l ) ~}$ & \\
\hline & \\
\hline
\end{tabular}




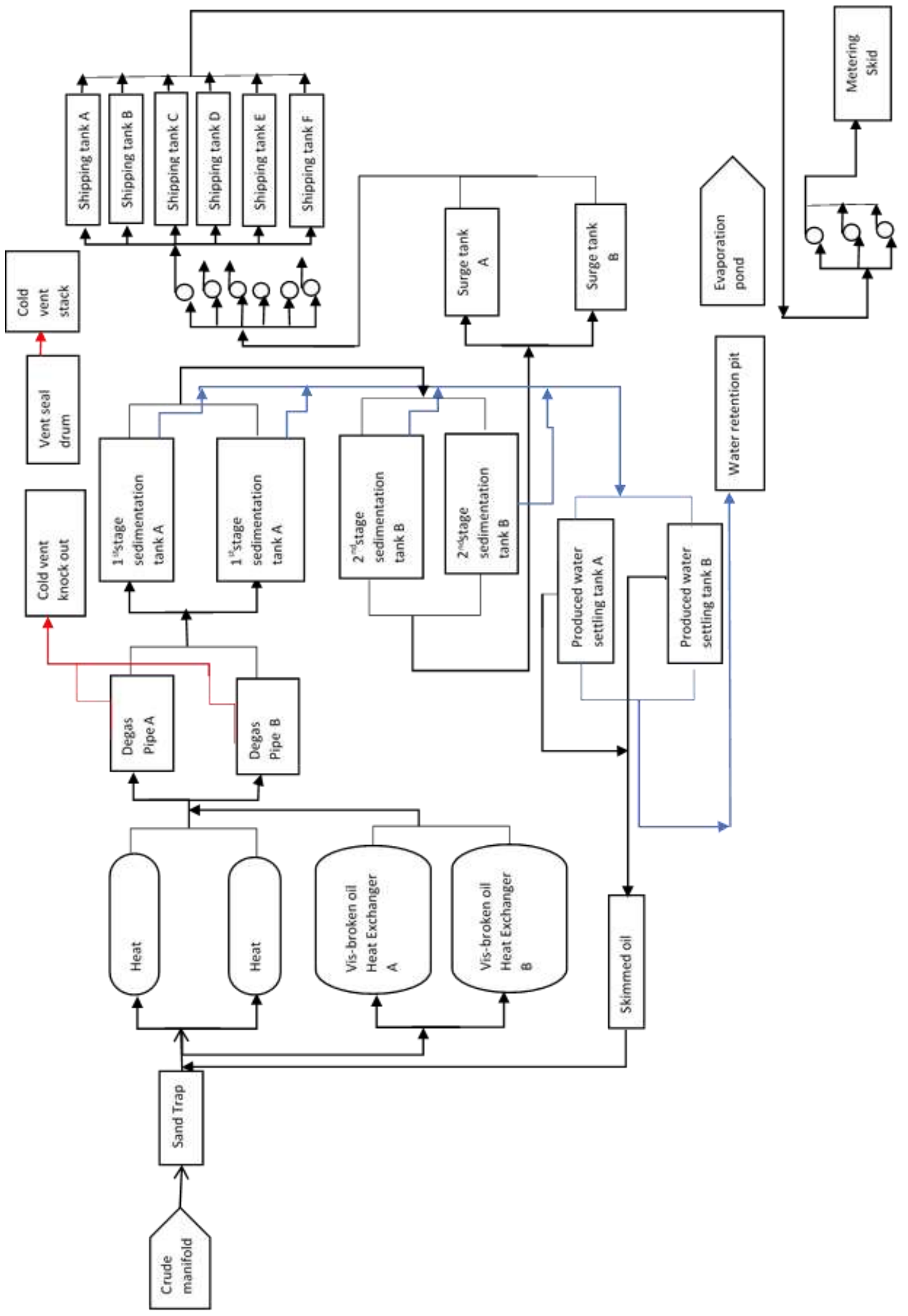

Figure 1: Flow diagram of Central Processing Facility 


\section{Net Present Value (NPV) calculations}

The cash flow (CF) and NPV were calculated. A lifetime of 30 years was assumed for the CPF. The interest rate was taken as $12 \%$. The flow rate of crude oil was assumed to be $40,000 \mathrm{bbl} / \mathrm{d}$ for the first six years and increased to $50,000 \mathrm{bbl} / \mathrm{d}$ afterwards. The net production of the crude is calculated after the removal of water and gas. The assumed price of the crude oil was taken as $\$ 60 / \mathrm{bbl}$. In the first two years investment is based on the fixed and working capitals. The net cash flow is calculated by deducting the operating cost and the investment from the income. The total net present value, was calculated from the net cash flow, i.e., net future value using the following formula [4].

$$
N P V=\sum_{n=1}^{n=t} \frac{N C F}{(1+r)^{n}}
$$

where the NPV is the total net present value, NCF is the net future value, $r$ is the interest rate, $n$ is the year, and $\mathrm{t}$ is the assumed project life.

\section{Sensitivity Analysis}

The variation impact of $\pm 35 \%$ of a number of parameters on NPV and the production cost were studied. The parameters include crude oil prices, feed flow rate of crude oil (barrels per day), concentration of silica nanoparticles ( $\mathrm{ppm}$ ), and prices of silica nanoparticles.

\section{Flowsheet Selection Options}

Two flowsheets were proposed: a traditional $\mathrm{CPF}$ and a $\mathrm{CPF}$ where a sonicator was added to introduce the silica nanoparticles. The flowsheets were compared based on an equal plant capacity and on a fixed annual crude oil processing basis. In the case of the similar plant capacity, the facility that uses silica nanoparticles was modified to be able to treat a higher feed flow rate. On the other hand, when the same feed flow rate is considered for both flowsheets, the sedimentation tanks were resized to reflect the added benefit of the reduction in sedimentation time provided with the use of silica nanoparticles.

\section{Results and Discussion}

\section{CPF capital and operating cost}

The calculations for the capital and operating costs of the CPF plant were computed. Table 4 shows the utilities cost breakdown. 
Table 4: Utilities cost breakdown

\begin{tabular}{lcccccc}
\hline Utility & $\begin{array}{c}\text { Estimated } \\
\text { Cost }\end{array}$ & $\begin{array}{c}\text { Updated } \\
\text { price } \mathbf{( 2 0 1 9 )}\end{array}$ & $\begin{array}{c}\text { Required } \\
\text { amount }\end{array}$ & Units & $\begin{array}{c}\text { Quantity per } \\
\text { year }\end{array}$ & $\begin{array}{c}\text { Total cost \$/ } \\
\text { year }\end{array}$ \\
\hline Process water $(\mathbf{\$} / \mathbf{t})$ & 0.3 & 0.4 & 18 & $\mathrm{~m}^{3} / \mathrm{h}$ & 157,680 & 63,765 \\
\hline Compressed air $\left(\mathbf{c} / \mathbf{m}^{3}\right)$ & 0.6 & 0.8 & 120 & $\mathrm{~m}^{3} / \mathrm{h}$ & $1,051,200$ & 850,203 \\
\hline Fuel oil $(\mathbf{\$} / \mathbf{t})$ & 100 & 134.8 & 992,712 & $\mathrm{MJ} / \mathrm{d}$ & $362,340,048$ & $8,654,343$ \\
\hline $\begin{array}{l}\text { Waste water } \\
\text { treatment }(\mathbf{\$} / \mathbf{t})\end{array}$ & 1.3 & 1.5 & 5,573 & $\mathrm{~m} / 3 / \mathrm{d}$ & 8,427 & 12,741 \\
\hline Total utilities & & & & & & \\
\hline
\end{tabular}

\section{Effect of varying key factors on NPV}

Figure 2 shows the effect of $\pm 35 \%$ change in key factors on the NPV. It is clear that the NPV is sensitive to changes in crude oil prices. A $\pm 35 \%$ change in crude oil prices would cause more than $\pm 40 \%$ change in NPV. All relations show linearity in their positive and negative changes. The second factor that has a great influence on the NPV is the feed flow rate.

\section{Effect on the production cost}

The production cost also has a direct relationship with the feed flow rate of the crude oil. On the other hand, the change in the nanoparticles' prices or concentration has a negligible effect on the production cost and the NPV.

\section{Cost of adding silica nanoparticles}

The financial study shows a negligible effect on the overall cost of adding silica nanoparticles on the NPV and the production cost. This is due to its small contribution when compared to the other major components.

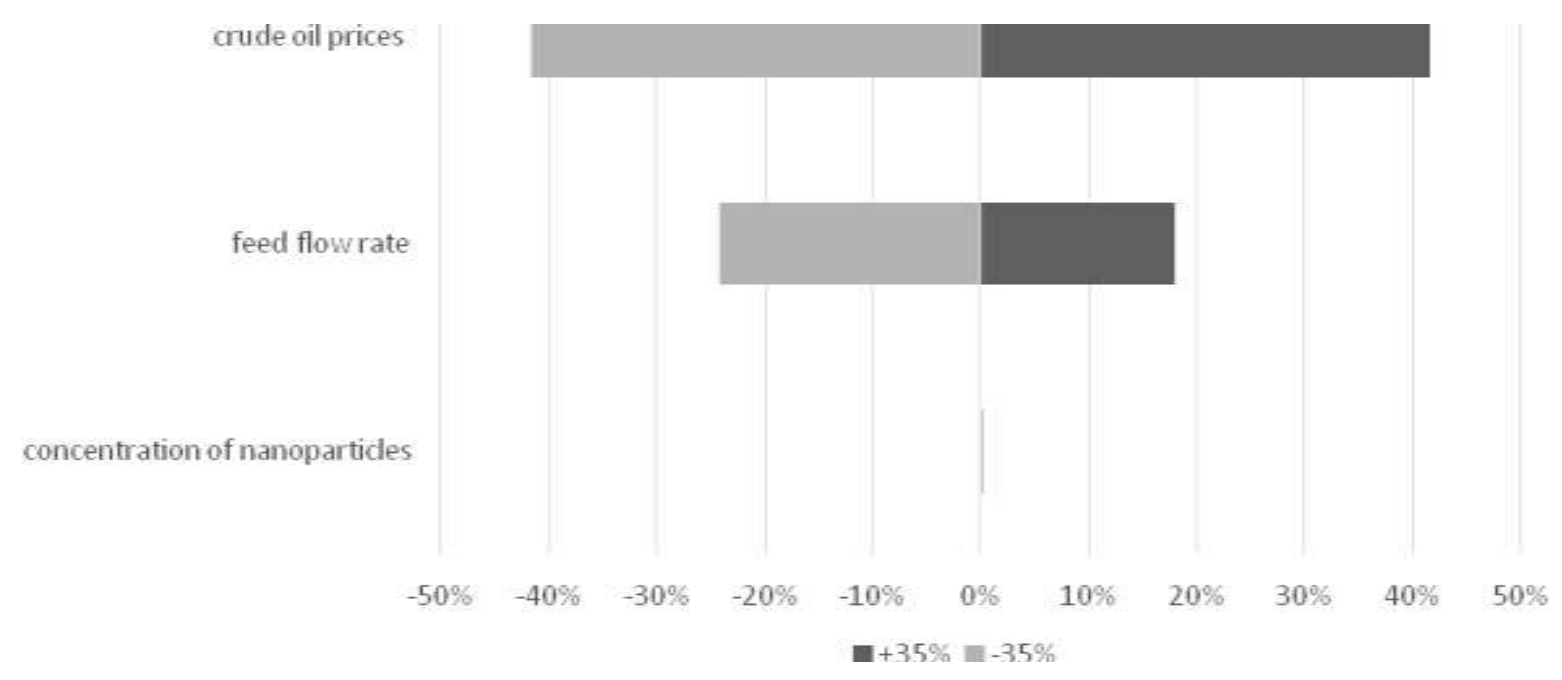

Figure 2: Effect of change in crude oil prices, feed flow rate and concentration of nanoparticles on NPV 


\section{Financial impact of adding silica nanoparticles}

\section{First flowsheet option: Same plant capacity basis}

As mentioned earlier, the required time for demulsification is reduced by $24 \%$ when silica nanoparticles are added. For the same plant capacity, adding silica nanoparticles may serve to reduce the required time inside the sedimentation tanks, which will allow for the processing of more crude oil. Thus, increasing the feed flow rate directly affects the production cost by decreasing it by $19 \%$ as shown in Table 5.

\section{Second flowsheet option: Same feed flow rate basis}

In the case of adding silica nanoparticles to a CPF, that handles the same flow rate, the acceleration in the demulsification process may serve to reduce the required sedimentation tank capacity. Table 6 shows the effect of this adjustment on the total estimated investment and accordingly, on the production cost.

Table 5: Effect of reducing the retention time on the increase in feed flow rate and on the production cost

\begin{tabular}{lcc}
\hline Retention time percentage decrease & Base case & Case with nanoparticles \\
\hline Flow rate $(\mathbf{b b l} / \mathbf{d})$ & 50,000 & 65,789 \\
\hline Production cost $\mathbf{( \$ / b b l )}$ & 3.3 & 2.6 \\
\hline Percentage change in production cost $(\boldsymbol{\%})$ & & $-19.0 \%$ \\
\hline
\end{tabular}

Table 6: Effect of reducing the retention time on reducing the required capacity of the sedimentation tanks and on the production cost

\begin{tabular}{lcc}
\hline & Base case & $\begin{array}{c}\text { Case with } \\
\text { nanoparticles }\end{array}$ \\
\hline Settling time in sedimentation tank (hours) & 8 & 6 \\
\hline Required capacity of sedimentation tank $\left.\mathbf{( m}^{\mathbf{3}}\right)$ & 5,000 & 3,800 \\
\hline Cost of equipment $\mathbf{( \$ )}$ & $2,000,000$ & $1,382,632$ \\
\hline Total investment million $\mathbf{( \$ )}$ & $329,981,798$ & $313,527,992$ \\
\hline Production cost $\mathbf{( \$ b b l )}$ & 3.2 & 3.1 \\
\hline Percentage change in production cost $\mathbf{( \% )}$ & & $3.7 \%$ \\
\hline
\end{tabular}

\section{Conclusion}

A techno-economic analysis was conducted for the use of silica nanoparticles in a CPF processing Fula heavy crude oil (Balila, Sudan). The study showed that the NPV is sensitive to changes in crude oil prices and feed flow rate. It is shown how the feed flow rate highly affects the production cost. It is clear that the overall cost of adding silica nanoparticles does not have a tangible effect on NPV or production cost. With the use of silica nanoparticles, flow sheet selection on equal plant capacity basis results in a $19 \%$ reduction in the production whereas comparison on fixed annual crude oil processing basis results in a reduction in production cost of only 3.7\%. The significant reduction in the production cost, assuming a comparison on an equal plant capacity basis, is not due to the improvement in 
demulsification but rather as a result of the higher throughput of processed crude oil due to the reduction in the time of treatment.

\section{Acknowledgments}

The authors are grateful for the financial support from the Sudanese Ministry of Higher Education and Scientific Research.

\section{References}

[1] Kokal, S. L. 2005. Crude oil emulsions: A state-of-the-art review. SPE Production \& facilities, 20, 513.

[2] Gandomkar, G., Bekhradinassab, E., Sabbaghi, S. \& Zerafat, M. 2016. Improvement of chemical demulsifier performance using silica nanoparticles. World Academy of Science, Engineering and Technology, International Journal of Chemical, Molecular, Nuclear, Materials and Metallurgical Engineering, 9, 585-588.

[3] Hassan, S. A., Abdalla, B. K. \& Mustafa, M. A. 2019. Addition of silica nano-particles for the enhancement of crude oil demulsification process. Petroleum Science and Technology, 37, 1603-1611.

[4] Toweler, G. \& Sinnott, R. 2009. Chemical engineering design: principles, practice and economics of plant and process design, Elsevier.

[5] Milligan D, M. J. 2019. Matches' engineering to chemical energy manufacturing metallurgical industries [Online]. Available: http://www.matche.com [Accessed 2 July 2019]. 